\title{
AGRICULTURA FAMILIAR E FUMICULTURA EM PILÕES/RN
}

\author{
Lauriciana Damares da Silva* \\ Boanerges de Freitas Barreto Filho**
}

Resumo: A agricultura familiar não restringe as atividades apenas a produção de alimentos, pelo contrário, a produção abarca vários tipos de culturas distribuídas pelas diversas regiões do país, como é o caso da produção fumageira que é desenvolvida, basicamente, por agricultores familiares. O trabalho tem como objetivo descrever a dinâmica da fumicultura no município de Pilões/ $\mathrm{RN}$, destacando as principais consequências associadas ao esgotamento da atividade. $\mathrm{O}$ ciclo fumageiro no município de Pilões/RN proporcionou pontos positivos e negativos, pois, ao mesmo tempo em que representou certa relevância para a economia local, também contribuiu para o esgotamento precoce dos recursos hídricos nos anos de estiagem, impactou negativamente a saúde dos envolvidos com o cultivo, especialmente os trabalhadores e reduziu a diversidade da produção agrícola dos agricultores familiares.

Palavras-chave: Agricultura familiar. Fumicultura. Dinâmica econômica. Pilões/RN.

\begin{abstract}
Family farming does not restrict activities only to food production, on the contrary, the production encompasses various types of crops distributed throughout the various regions of the country, as is the case of ta production that is basically developed by family farmers. The objective of this work is to describe the dynamics of smoking in the municipality of Pilones/RN, highlighting the main consequences associated with the exhaustion of the activity. The cycle of tobacco cultivation in the municipality of Pilões/RN provided positive and negative points, because, while it represented some relevance for the local economy, it also contributed to the early depletion of water resources in the years of drought, negatively impacted the health of those involved with cultivation, especially workers and reduced the diversity of agricultural production of family farmers.
\end{abstract}

Keywords: Family farming. Tobacco culture. Economic dynamics. Pilões-Rio Grande do Norte-Brazil.

\footnotetext{
* Universidade do Estado do Rio Grande do Norte - UERN.

** Bacharel em Ciências Econômicas pela Universidade do Estado do Rio Grande do Norte (2002). Especialista em Desenvolvimento Regional e Planejamento Territorial pela UERN. Mestrado Acadêmico em Planejamento e Dinâmicas Territoriais no Semiárido.
} 


\section{Introdução}

Segundo Mattei (2014), são os agricultores familiares que produzem os alimentos que atendem as necessidades alimentícias do povo brasileiro, com $34 \%$ da produção de arroz; $46 \%$ da produção de milho; $70 \%$ da produção de feijão; $38 \%$ da produção de café e $58 \%$ da produção de leite são originadas da agricultura familiar.

A mudança de comportamento do Estado em relação ao segmento agrícola familiar se deu com a criação do Programa Nacional de Fortalecimento da Agricultura Familiar (PRONAF), pois representou a primeira iniciativa do Estado direcionada especificamente para a categoria dos agricultores familiares. Anteriormente, os agricultores familiares tinham que disputar os recursos disponíveis para financiamento com os grandes proprietários, aspecto por se si só já evidencia as dificuldades para conseguir acessar recursos via setor bancário. Saliente-se que o reconhecimento não se deu pela benevolência governamental, mas decorrente de uma importante conquista dos movimentos sociais ligados à agricultura (SCHNEIDER; MATTEI; CAZELLA, 2004).

É válido destacar que a agricultura familiar não restringe suas atividades apenas para a produção de alimentos, pelo contrário, acontece com vários tipos de lavouras distribuídas por diversas regiões do território brasileiro. De acordo com a Associação de Fumicultores do Brasil - AFUBRA (2019), a produção fumageira é desenvolvida, no Brasil, basicamente pela agricultura familiar.

Saliente-se que a atividade é realizada no Brasil desde o século XVII, constituindo-se, inclusive, numa fonte importante de renda da coroa portuguesa e num destacado instrumento da própria reprodução da sociedade escravista ${ }^{1}$ (LOPES, 2005). Vale destacar, como faz o próprio Lopes (2005), que a literatura histórica não conferiu grande espaço para tratar da atividade, mas que, segundo as fontes que trataram do assunto, tinha-se uma produção realizada em pequenas porções de terras, com pouco uso de escravos e recorrendo ao trabalho da mão de obra familiar. O autor, baseando-se em Prado Júnior, sustenta que o fato da atividade ser realizada em pequenas áreas de terra diz respeito ao seu caráter técnico (exigência de maiores cuidados), mas não se prescindia do uso de escravos na atividade (aspecto que sugere a relevância econômica alcançada) (LOPES, 2005).

A questão técnica parece ser a explicação para que a fumicultura tenha continuado a ser, predominantemente, associada ao uso de quantidade reduzida de terras por cada produtor e, por isso, a agricultura familiar passou a ser o principal segmento produtor de fumo, inclusive em algumas áreas do Semiárido, como é o caso do município de Pilões/RN. 
A atividade fumicultora possui relevância econômica, pois oportuniza a geração de emprego e renda para áreas que dispõem de poucas oportunidades, embora seja sempre envolta numa série de questionamentos sobre o balanço entre impactos positivos versus negativos.

Desse modo, tem-se a seguinte problemática: qual foi o legado sócio-econômico-ambiental da atividade fumageira praticada em Pilões/RN? E como objetivo geral descrever a dinâmica da fumicultura no município de Pilões/RN e as consequências associadas ao esgotamento da atividade.

Acredita-se que o trabalho pode contribuir para o debate sobre a produção fumageira na agricultura familiar, destacando-se os aspectos socioambientais e econômicos para municípios com base econômica muito dependente de recursos externos, como é o caso de boa parte dos municípios do interior do Nordeste, especialmente os do Rio Grande do Norte. Ademais, a produção de dados e informações sobre a ascensão e queda do cultivo de fumo no município de Pilões/RN pode servir de alerta para outras localidades que ainda dependem de tal atividade, isso porque a fumicultura representou oportunidades de geração de emprego e renda para diversas famílias diretamente envolvidas no cultivo e para outros segmentos econômicos da cidade, como o comércio e a prestação de serviços pessoais.

Conforme Gil (2002), as pesquisas descritivas têm o objetivo de descrever as características de determinadas populações ou fenômeno ou estabelecer relações entre as variáveis. A pesquisa contou com uma revisão bibliográfica, sobre as temáticas da agricultura familiar e fumicultura e de como esses processos se desenvolveram no Brasil. Além da pesquisa bibliográfica, o estudo conta com um levantamento de dados através da pesquisa documental. Sendo assim, foram extraídos dados de artigos, dissertações, teses, além de consultas em sites do IBGE e da AFUBRA, dentre outros.

Ademais, o estudo conta com uma pesquisa de campo, com a finalidade de identificar a realidade da localidade em análise. Dessa forma, foi fundamental a realização de visitas aos locais de produção, como os campos utilizados para os plantios no município. Por fim, foram realizadas entrevistas semiestruturadas com alguns atores locais, como os antigos trabalhadores, produtores e agentes públicos a fim de melhor esclarecer a realidade existente.

Além da Introdução, o trabalho foi estruturado em três seções e as conclusões. A primeira seção apresenta algumas considerações sobre a agricultura familiar, destacando as características do segmento e as relações com a agroindústria. A segunda aborda a fumicultura nas diferentes escalas espaciais, através da exposição de dados relativos ao país e o Rio Grande do Norte. A terceira apresenta os resultados e discussões do trabalho. Em seguida são apresentadas as conclusões. 


\section{Breves considerações sobre agricultura familiar no Brasil}

Segundo o Ministério da Agricultura, Pecuária e Abastecimento (MAPA, 2017), as informações do Censo Agropecuário de 2006 apontaram que:

[...] a agricultura familiar constitui a base econômica de $90 \%$ dos municípios brasileiros com até 20 mil habitantes; responde por 35\% do produto interno bruto nacional e absorve $40 \%$ da população economicamente ativa do país. O setor produz $87 \%$ da mandioca, $70 \%$ do feijão, $46 \%$ do milho, $38 \%$ do café, $34 \%$ do arroz e $21 \%$ do trigo do Brasil. Na pecuária, é responsável por $60 \%$ da produção de leite, além de 59\% do rebanho suíno, 50\% das aves e 30\% dos bovinos do país. O setor também emprega $74 \%$ das pessoas ocupadas no campo, de 10 postos de trabalho no meio rural, sete são de agricultores familiares. Constate-se que a agricultura familiar dispõe de um papel fundamental na produção de alimentos e na geração de empregos, gerando 7 em cada 10 ocupações no meio rural e respondendo por parte substancial da produção de alimentos no país.

O debate sobre a importância da agricultura familiar tem ganhado cada vez mais destaque nos últimos anos, principalmente porque desempenha importantes papeis socioeconômicos nas diversas regiões do país, dentre os quais: fornecimento de alimentos para os habitantes das cidades e para o autoconsumo das famílias produtoras, geração de emprego e renda e fixação de habitantes nas zonas rurais.

O termo agricultura familiar passou a ganhar destaque na década de 1990, quando o Governo Federal incluiu o segmento na elaboração de programas e ações. Até então, utilizavam-se expressões diversas para se fazer referência ao universo da agricultura familiar, tais como: "produtor de subsistência", "produtor de baixa renda" e "pequeno produtor", deste modo o segmento passou a ser considerado, conceitualmente, em períodos recentes. Assim, como descrevem Schneider e Cassol (2013, p. 5):

O surgimento e o reconhecimento da agricultura familiar no Brasil é muito recente e deve-se à três fatores igualmente importantes. O primeiro tem a ver com a retomada do papel do movimento sindical após o fim da ditadura militar; o segundo está relacionado ao papel dos mediadores e intelectuais, especialmente cientistas sociais que debateram o tema no início da década de 1990; e o terceiro fator está relacionado ao papel do Estado e das políticas públicas, que passaram a reconhecer este setor e dar-lhe visibilidade a partir da criação do Programa Nacional de Fortalecimento da Agricultura Familiar (PRONAF). 
O Programa Nacional de Fortalecimento da Agricultura Familiar (PRONAF) passou a desempenhar importante papel de estímulo para o segmento, principalmente para aqueles agricultores familiares com maior capacidade de capitalização e nível mais satisfatório de articulação. Tais agricultores conseguiram acessar os recursos e melhoraram as condições de produção e, consequentemente, tiveram ganhos de produtividade (SCHNEIDER; CASSOL, 2013).

Formalmente a agricultura familiar corresponde a toda forma de cultivo da terra e produção rural cuja gestão e mão de obra sejam majoritariamente provenientes do núcleo família. Segundo a Lei Federal n 11.326, de 24 de julho de 2006, no artigo $3^{\circ}$, para se enquadrar como agricultura familiar são necessárias três características primordiais, sendo elas: não dispor de área maior do que quatro módulos fiscais; a mão de obra tem de ser predominantemente familiar e; o maior percentual da renda deve ser proveniente da agropecuária (BRASIL, 2006).

Saliente-se que o reconhecimento do segmento da agricultura familiar como uma atividade importante foi algo relativamente recente a para tal situação foram relevantes as pesquisas e estudos que demonstraram as contribuições do setor para o desenvolvimento social e para a economia do país, revelando-se que o segmento movimenta bilhões de reais anualmente, que é responsável por mais de $50 \%$ da produção dos alimentos que são consumidos pela população, que gera muitos empregos e renda e contribui, decisivamente, para manter parte da população residindo no meio rural (DAMASCENO; KHAN; LIMA, 2011).

Verifica-se que a literatura especializada é abundante sobre a propalada supremacia da grande propriedade como o tipo ideal de estabelecimento para receber os estímulos (subsídios e crédito) do Estado, em virtude de sua superioridade técnica e por ser capaz de se integrar ao mercado a partir da utilização de insumos agroquímicos e equipamentos modernos (tratores, implementos, equipamentos etc.) e, por conseguinte, atender, por um lado, aos interesses da indústria de máquinas e equipamentos para a agricultura, bem como da indústria química que fabrica pesticidas, defensivos, fertilizantes e dos setores que produzem rações, suplementos e medicamentos para os rebanhos, constituindo-se, portanto, num movimento de sustentação e ampliação do mercado para tais produtos.

Esse tipo de entendimento sobre a adequação da grande propriedade para recepcionar os avanços técnicos e científicos aplicados a agropecuária acabou por se configurar como uma espécie de modelo para a modernização da agricultura familiar. Assim, nem todos os tipos de agricultores familiares se beneficiaram dos recursos disponibilizados através do PRONAF quando de sua fase inicial de funcionamento, 
direcionando-se quase que exclusivamente para aqueles com um grau maior de integração ao segmento produtor de agroquímicos.

Noutra perspectiva, observa-se à integração para frente. Em que a agricultura familiar se tornou um elo das cadeias agroindustriais, destacando-se o fornecimento de animais para abate e processamento pelos grandes frigoríficos, o fornecimento de cana de açúcar para as usinas produtoras de açúcar e etanol, o fornecimento de folhas de fumo para a fabricação de cigarros e charutos, dentre outras atividades.

Observa-se que os agricultores familiares integrados têm que cumprir uma série de exigências estabelecidas em contratos para entregarem produtos adequados aos padrões estabelecidos, além de assegurarem o fornecimento regular nos prazos estabelecidos.

Conforme ressalta Dutra (2013, n. p.):

Um dos exemplos significativos é o dos agricultores que por falta de alternativas em outras produções (leite, conservas e frangos...) ingressam na fumicultura, produção essa destinada ao mercado externo, articulando a lógica de conexão do local ao global em que a agricultura familiar é um dos elementos que compõem essa dinâmica. A fumicultura, que tem por objetivo atender às necessidades do mercado externo e que se desenvolve sob a lógica, em que articulam-se diferentes escalas de poder, é um exemplo do novo momento ao qual está submetida a agricultura brasileira.

Esse sistema de integração é uma válvula de escape para os grupos empresariais, de forma que diminuem os perigos que estão presentes nas atividades agrícolas e consequentemente diminuem suas responsabilidades, repassando-as para o segmento familiar capturado, através da contratualização.

Sobre a caracterização dos estabelecimentos familiares produtores de fumo e os resultados produtivos, observou-se que:

[...] a produção desta cultura (chamada de 'fumos em folha') ocorre principalmente em pequenos estabelecimentos especializados, de até 20 ha, que ocupam, prioritariamente, mão de obra familiar, com mais de 14 anos de idade. Além disso, a produção tem caráter comercial, visto que mais de 95\% da produção é comercializada principalmente com usinas de beneficiamento. Mesmo operando com uma tecnologia produtiva essencialmente manual, o valor da produção chega a mais de $\mathrm{R} \$ 5$ mil por ha e ao ano (US\$ 3.300,00) (SILVA, LIBARDONI, FARIAS, 2013, p. 11).

Nesse sentido, verifica-se a realização do cultivo em estabelecimentos familiares, com tamanho reduzido, baixo aporte tecnológico, com grau acentuado de 
especialização produtiva, atrelado ao setor de beneficiamento e com resultados econômicos razoavelmente satisfatórios.

\subsection{A fumicultura no Brasil e no Rio Grande do Norte}

Com a fixação dos colonos portugueses o tabaco passou a ganhar destaque e a ser produzido tanto para o consumo como para a comercialização. Também no período de ocupação holandesa em terras do Nordeste se observou a importância da comercialização do produto, segundo Bonato (2007): "Durante a ocupação holandesa em Pernambuco (início do século XVII), o fumo produzido ocupou papel importante na carteira comercial de produtos oferecidos pela Companhia das Índias Ocidentais" (BONATO, 2007, p. 5).

Ainda, segundo Bonato (2007, p. 5):

O fumo brasileiro passou a ter três destinos principais. O produto considerado de primeira e segunda qualidade era exportado para Lisboa e a maior parte (cerca de 60\%) era reexportada para outros países europeus. Uma outra parte, considerado fumo de terceira qualidade, servia também de moeda para o comércio de escravos com a África no período colonial, o restante destinava-se ao consumo interno. Até 1850, o fumo baiano passou a ser o principal gênero de comércio no escambo dos escravos com a África, chegando a representar 30\% das exportações de fumo no Brasil Colonial.

Para Lopes (2004), a produção de tabaco passou a ser um subciclo na mesma época do açúcar e se tornou uma importante moeda de troca por escravos africanos, mas com características distintas da atividade açucareira.

As questões relacionadas à atividade, como se viu, remonta ao período colonial, cuja estruturação sugere melhor adequação da exploração em áreas de menor porte, associando-se o trabalho escravo e a mão de obra familiar, com vista a exportação e, neste sentido, revestindo-se de importância estratégica, posto que servia de "moeda" para a aquisição de escravos na costa africana.

Observa-se, ao longo das décadas do século XX, um crescimento gradual da produção de fumo no país, com uma ascensão forte a partir dos anos 2000, conforme disposto no Gráfico 1. 


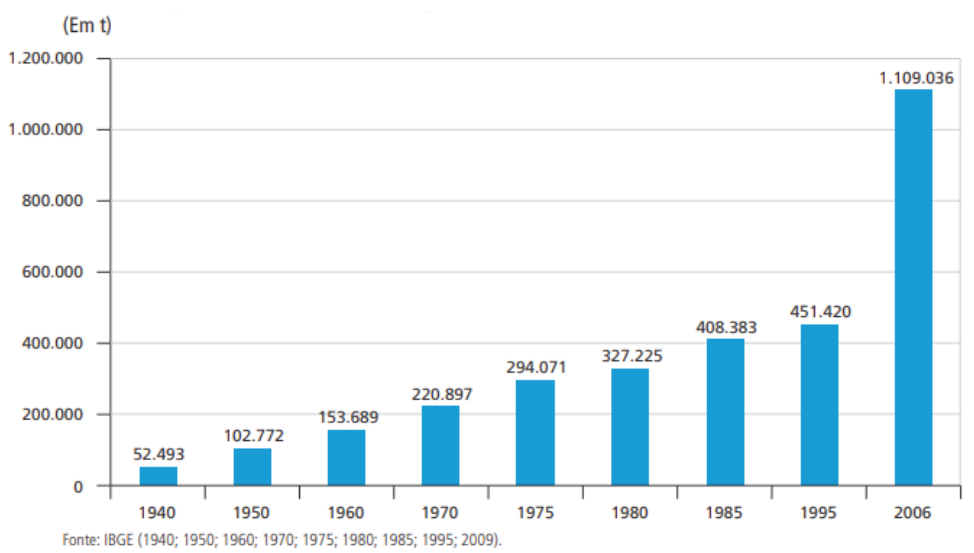

Gráfico 1 - Quantidade produzida nas lavouras temporárias de fumo em folha - Brasil (1940-2006) (em toneladas) Fonte: Silva, Libardoni, Farias (2013, p. 10).

Verifica-se que o setor passou por períodos de expansão no decorrer dos anos, ganhando ou perdendo relevância econômica nas diversas áreas do país em que o cultivo ocorreu. Segundo a Associação dos Fumicultores do Brasil (AFUBRA) ${ }^{2}$, a década de 1950 foi a mais difícil para o ramo, em decorrência de uma crise que se abateu sobre a atividade. A produção de fumos não aceitos pelo mercado gerou estoques elevados. Com isto, a indústria estabelecia os preços que lhe convinha e nem sempre comprava toda a produção dos cultivadores, gerando tensões que serviram como incentivo para a criação da associação representativa dos fumicultores do Brasil (AFUBRA, 2019).

A produção do tabaco se estende por várias partes do país, ocorrendo de forma mais acentuada na região Sul, o que corresponde a 98\% de toda a produção nacional, com 14 mil produtores integrados, um universo de aproximadamente 615 pessoas participa do ciclo produtivo no meio rural, somando uma receita bruta anual de R\$ 5 bilhões. (REVISTA AMANHÃ, 2016).

Alguns outros estados apresentam índices de produção inferiores, porém, significativos para as localidades envolvidas na produção, destacando-se as produções de Alagoas e Bahia no Nordeste. A produção nos demais estados do Nordeste ocorre em alguns municípios, como no Rio Grande do Norte, em que o cultivo é realizado, por exemplos, em Alexandria/RN e Pilões/RN.

De acordo com Gama e Carneiro (2011) e Pontes (2016), no Rio Grande do Norte, o cultivo de fumo se intensificou na década de 1980, concentrando-se as operações nos municípios de Alexandria e Pilões, sendo a atividade iniciada através da 
atuação de agentes arregimentadores a serviço da Souza Cruz. Alguns agricultores familiares foram convencidos que o cultivo de fumo, com a compra garantida pela empresa, seria uma oportunidade para geração de renda agrícola, tendo em conta também o declínio da produção algodoeira.

O Projeto RN Sustentável mapeou, com base nos dados do Censo Agropecuário (IBGE, 2006), as áreas que apresentavam o cultivo do produto. Observa-se na Figura 1 que a concentração de produção da lavoura se concentrava no Alto Oeste Potiguar.

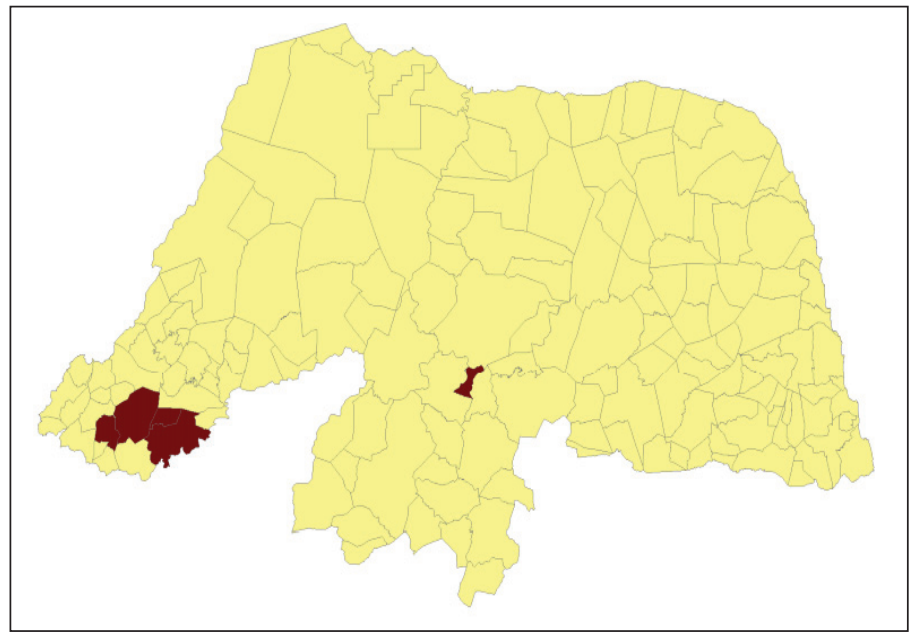

Figura 1 - Áreas com cultivo de fumo no RN Fonte: RN Sustentável (2013. p. 18).

De acordo com o RN Sustentável, observava-se o cultivo de fumo em São Vicente, Marcelino Vieira, José da Penha, Alexandria e Pilões, sendo os dois últimos responsáveis por $76 \%$ da produção potiguar. A produção total no estado resultou em $\mathrm{R} \$ 1.734 .000,00$, representando apenas $0,29 \%$ do valor total das lavouras temporárias e 0,14\% do PIB agropecuário (RN SUSTENTÁVEL, 2013, p. 18).

A Tabela 1 apresenta os dados disponíveis sobre a produção de fumo em folha no RN no período mais recente (2013-2009). 
Tabela 1 - Produção de fumo em folha no RN (2013-2009)

\begin{tabular}{cccccc}
\hline Ano & $\begin{array}{c}\text { Quantidade } \\
(\mathbf{t})\end{array}$ & $\begin{array}{c}\text { Valor da produção } \\
(\mathbf{R} \mathbf{S})\end{array}$ & $\begin{array}{c}\text { Área plantada } \\
(\mathbf{h a})\end{array}$ & $\begin{array}{c}\text { Área colhida } \\
(\mathbf{h a})\end{array}$ & $\begin{array}{c}\text { Rendimento médio } \\
(\mathbf{k g} / \mathbf{h a})\end{array}$ \\
\hline $\mathbf{2 0 1 3}$ & 10 & $41.000,00$ & 16 & 16 & 625 \\
\hline $\mathbf{2 0 1 2}$ & 14 & $97.000,00$ & 25 & 25 & 560 \\
\hline $\mathbf{2 0 1 1}$ & 115 & $1.313 .000,00$ & 130 & 130 & 884 \\
\hline $\mathbf{2 0 1 0}$ & 166 & $1.743 .000,00$ & 195 & 195 & 851 \\
\hline $\mathbf{2 0 0 9}$ & 215 & $1.846 .000,00$ & 241 & 241 & 892 \\
\hline
\end{tabular}

Fonte: IBGE (2019).

Os dados da Produção Agrícola da Lavoura Temporária do IBGE indicam uma produção decrescente, como também reduções das áreas plantadas e colhidas e do rendimento médio, consequentemente, resultando na queda acentuada dos valores da produção de fumo em folha no Rio Grande do Norte.

De acordo com Gama e Carneiro (2011, p. 38):

A Souza Cruz começou a se territorializar no município de Pilões a partir de 1986, através de três fumicultores. O convite para o plantio do fumo partiu da iniciativa de um Orientador da Souza Cruz que prestava assistência técnica ao município de Alexandria. Os fumicultores acreditavam que a cultura do fumo era de grande importância para o desenvolvimento interno, bem como para o progresso social e econômico do município. A partir desse pensamento e entendimento, começaram a desenvolver essa cultura nas imediações do açude público municipal.

Apurou-se que a fumicultura foi introduzida no município de Pilões/RN através da ação da empresa Souza Cruz, utilizando-se do trabalho de agricultores familiares e da disponibilidade de água existente no Açude Público de Pilões/RN, manancial utilizado para o abastecimento da cidade.

\section{Resultados e discussões}

O povoado de Pilóes surgiu por volta de 1745 , na época ainda uma fazenda pertencente ao capitão João Leitão Arnoso, famoso por ser um grande proprietário de terras criadoras de gado, onde havia sempre a necessidade de adquirir mais terras para melhor acomodar o rebanho. O crescimento da Fazenda dos Pilões atraiu trabalhadores com suas famílias e o povoado foi ganhando novas construções, como a capela, residências e pequenos estabelecimentos comerciais (IBGE, 2017). 


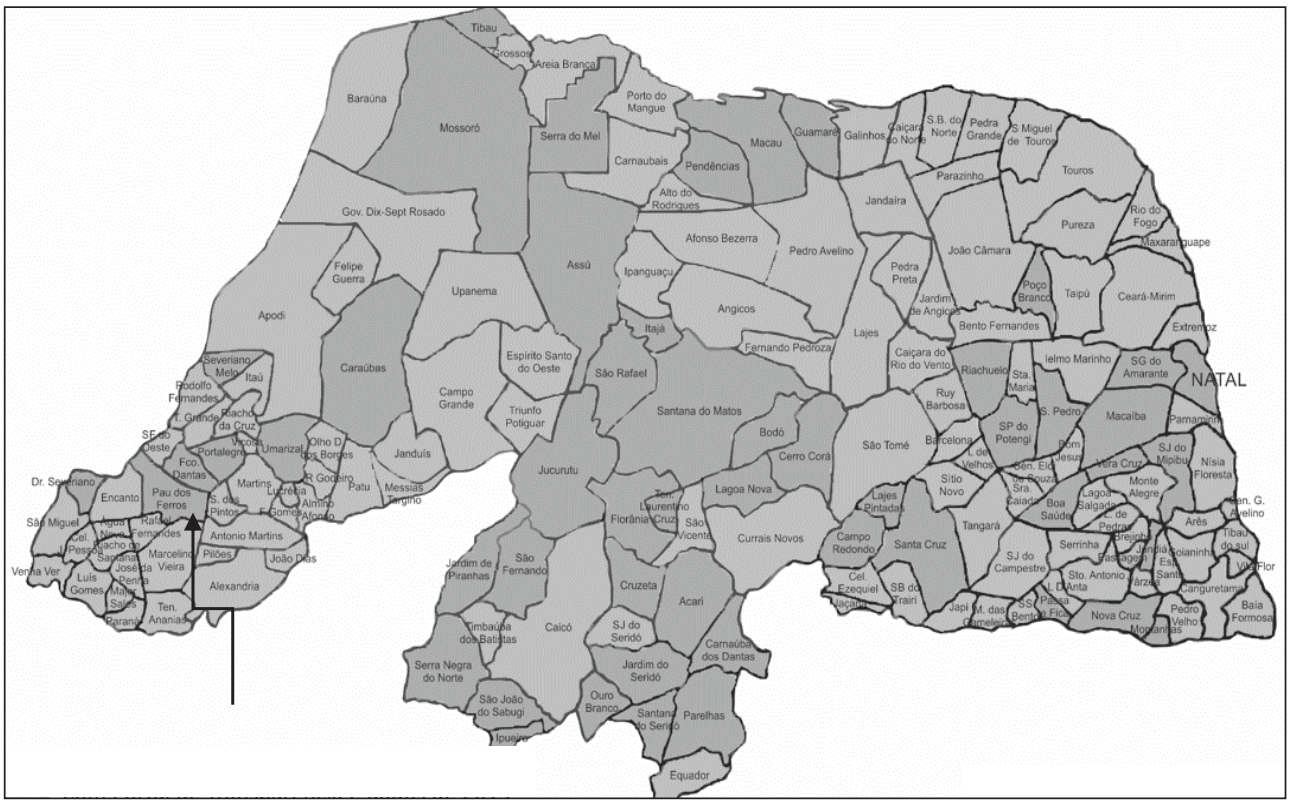

Figura 2 - Mapa Político do Rio Grande do Norte - Localização de Pilões.

Fonte: IBGE (2019).

Segundo o Censo Demográfico do Instituto Brasileiro de Geografia e Estatística (IBGE), em 2010, o município tinha uma população de 3.453 habitantes. A densidade demográfica local era de $41.76 \mathrm{hab} . / \mathrm{km}^{2}$. Atualmente, a população estimada pelo IBGE é de 3.806 pessoas. O Índice de Desenvolvimento Humano (IDH) apurado para 2010 foi de 0,614, sendo assim considerado um município de médio desenvolvimento (IDHM entre 0,600 e 0,699), em que: "A dimensão que mais contribui para o IDHM do município é Longevidade, com índice de 0,777 , seguida de Renda, com índice de 0,566, e de Educação, com índice de 0,527” (IBGE, 2010; 2019; PNUD, 2014).

Segundo Sousa e Barreto Filho (2017, p. 05-6):

As características econômicas mais significativas se compatibilizam com os demais municípios do Alto Oeste Potiguar, cujos dados para o ano de 2014 indicam uma participação 29,75\% do setor de serviços (considerando também a Administração, saúde e educação públicas e Seguridade Social a participação sobe para 90,5\%), comprovando a elevada dependência de fontes externas de recursos (transferências constitucionais, como o Fundo de Participação dos Municípios, e transferências diretas aos cidadãos, com destaques para a Previdência Rural e Bolsa Família), com participação 
incipiente da indústria $(3,28 \%)$ na composição do Produto Interno Bruto e participação modesta do setor agropecuário $(6,22 \%)$, especialmente no último quinquênio em virtude da seca.

De acordo com o IBGE (2016), o Produto Interno Bruto per capita do município, em 2016, foi de $\mathrm{R} \$ 8.642,35$. Pilões/RN se caracteriza por ser um município economicamente agrícola, onde destaca-se pelo e cultivo de feijão e milho. As demais fontes de renda familiares provem de programas de transferência de renda, aposentadorias e empregos públicos.

Durante o período em que foi cultivado no município, o fumo representou uma das principais fontes de renda, tendo em vista se constituir na principal atividade geradora de renda, conforme dados da Tabela 2. Mesmo havendo outras atividades ligadas à agricultura, o fumo se sobressaiu em termos de renda gerada pela produção.

Tabela 2 - Produção de fumo em folha Pilões/RN (2013-2009)

\begin{tabular}{cccccc}
\hline Ano & $\begin{array}{c}\text { Quantidade } \\
(\mathbf{t})\end{array}$ & $\begin{array}{c}\text { Valor da produção } \\
(\mathbf{R} \$)\end{array}$ & $\begin{array}{c}\text { Área plantada } \\
(\mathbf{h a})\end{array}$ & $\begin{array}{c}\text { Área colhida } \\
(\mathbf{h a})\end{array}$ & $\begin{array}{c}\text { Rendimento médio } \\
(\mathbf{k g} / \mathbf{h a})\end{array}$ \\
\hline $\mathbf{2 0 1 3}$ & - & - & - & - & - \\
\hline $\mathbf{2 0 1 2}$ & - & - & - & - & - \\
\hline $\mathbf{2 0 1 1}$ & 54 & $669.000,00$ & 60 & 60 & 900 \\
\hline $\mathbf{2 0 1 0}$ & 58 & $576.000,00$ & 64 & 64 & 906 \\
\hline $\mathbf{2 0 0 9}$ & 63 & $564.000,00$ & 64 & $64 \mathrm{~B}$ & 984 \\
\hline
\end{tabular}

Fonte: IBGE (2019).

A Tabela 2 traz um ranking da produção de fumo praticada no município de Pilões/RN no período de 2009 a 2013. Verifica-se a redução da quantidade produzida, com diminuição da área plantada e colhida e do rendimento médio por hectare, comportamento similar ao verificado com a produção em todo estado (Tabela 1). No biênio 2012/2013 não ocorreu mais a produção, sendo decorrente do agravamento da estiagem. Da mesma forma em que ocorreu no restante do estado, também não ocorreu produção de fumo no período mais recente (2014-2018).

Em relação ao sexo, todos os produtores identificados no município são do sexo masculino, distribuindo-se nas seguintes faixas etárias: $20 \%$ com até 35 anos, $40 \%$ acima de 35 anos até 45 anos, 20\% acima de 55 anos até 65 anos e 20\% acima de 65 anos. Verifica-se que os produtores ainda se enquadram em faixas etárias produtivas e que não foi por problemas associados a idade mais avançada que a produção foi paralisada, como se observa em boa parte das propriedades dos agricultores familiares a presença de pessoas com idades mais avançadas. 
Em relação a obtenção de crédito do PRONAF, $80 \%$ dos produtores nunca foram contemplados e $20 \%$ receberam poucas vezes, mas jamais utilizaram ou aplicaram tais recursos na atividade fumageira. Aliás, nenhum produtor de fumo tentou acessar outro tipo de financiamento ou linha de crédito agrícola para qualquer outra finalidade. Compreendendo todas as fontes de renda, observa-se que $60 \%$ das famílias têm nível de rendimentos acima de um salário mínimo podendo chegar até dois e 40\% conseguem obter de dois até três salários mínimos.

Quando considerado apenas o nível de rendimento anual proveniente da agropecuária, tendo o ano de 2018 como referência, observou que todos os entrevistados afirmaram dispor de até um salário mínimo. Tal aspecto evidencia um rendimento anual proveniente da atividade agropecuária muito baixo, sendo decorrente, segundo foi apurado, da forte seca que assolou a região ao longo de cinco anos e que em 2018 ainda representou muita dificuldade para os produtores pesquisados. Quando indagados sobre a principal causa para cessarem a produção de fumo, 100\% dos produtores apontaram a falta de água para realizar a irrigação das plantações.

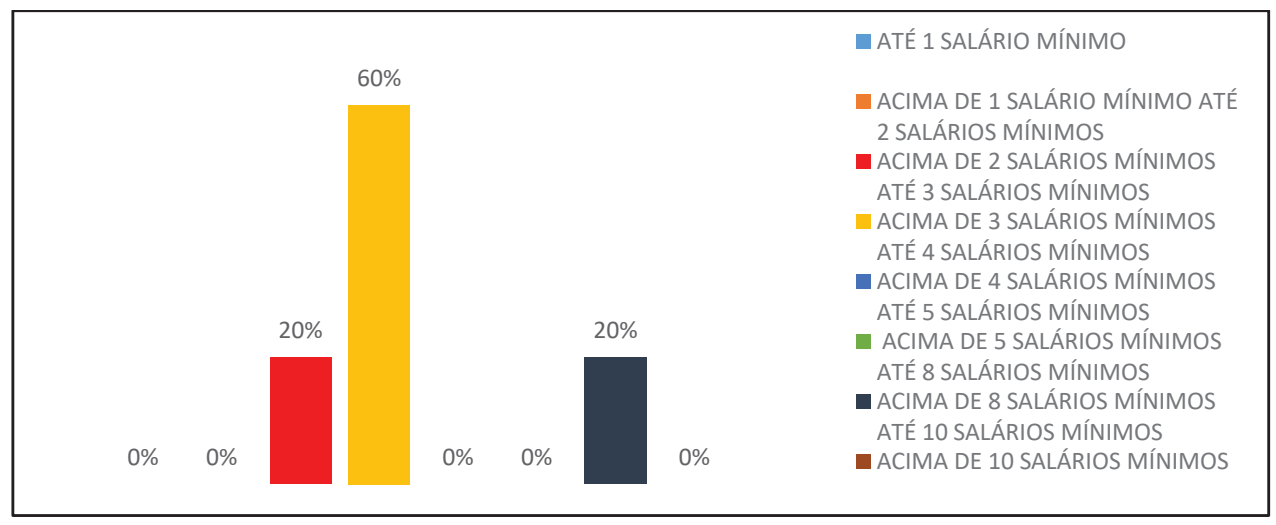

Gráfico 3 - Nível de rendimento anual proveniente da fumicultura Pilões/RN (referência: último ano em que produziu fumo)

Fonte: Pesquisa de campo (2019).

Observa-se no Gráfico 3 os rendimentos dos produtores advindos da fumicultura, tendo o último ano de produção como base, onde $60 \%$ destes declaram ter ganho renda equivalente acima de três salários mínimos podendo chegar até quatro; $20 \%$ considera ter ganhado acima de dois salários mínimos podendo chegar até três; e $20 \%$ alega ter obtido acima de oito salários mínimos podendo chegar até dez. 


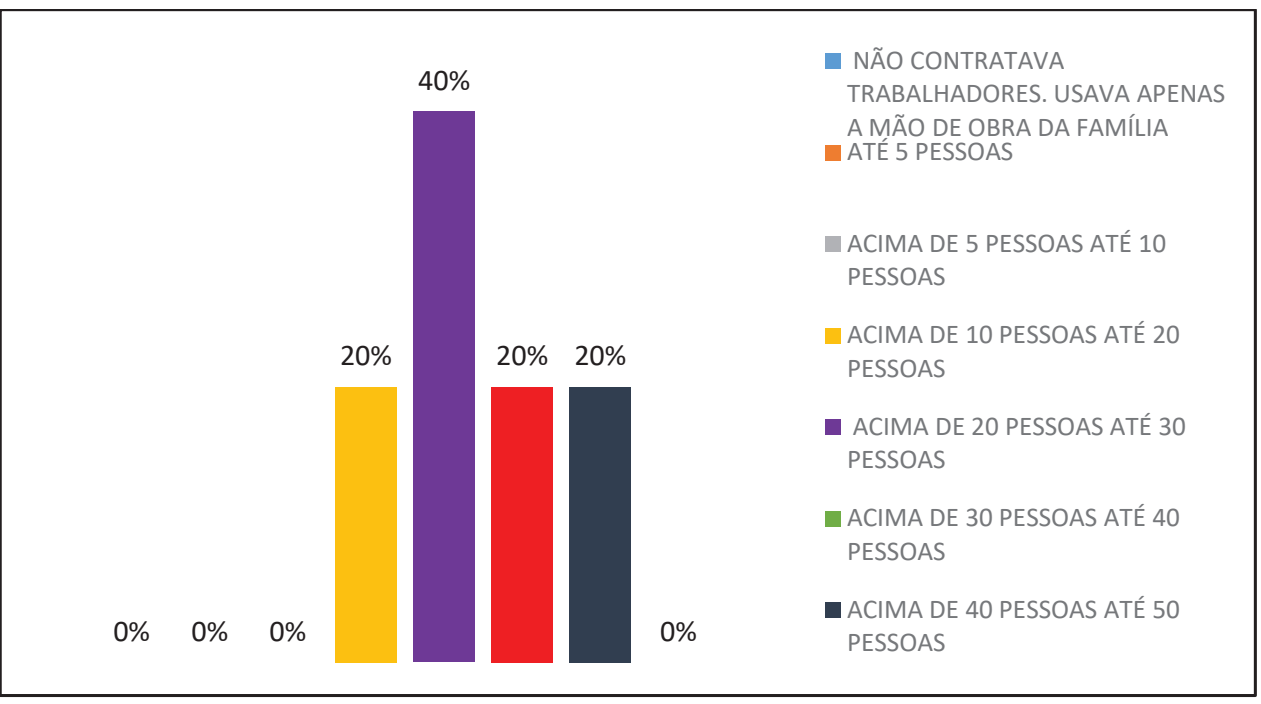

Gráfico 4 - Número médio de pessoal contratado para colheita/preparo das folhas para entregar a empresa - Pilões/RN (referência: último ano em que produziu fumo)

Fonte: Pesquisa de campo (2019).

No período de preparo e colheita das folhas para entregar a empresa, observa-se a necessidade de mais trabalhadores, diferente da necessidade de bem menos trabalhadores para iniciar o cultivo. Constata-se no Gráfico 4 que $20 \%$ dos produtores precisavam de 10 até 20 pessoas, $40 \%$ demandavam de 20 até 30 pessoas; $20 \%$ necessitavam acima de 40 até 50 pessoas, e $20 \%$ podendo chegar acima de 50 pessoas. É valido ressaltar a importância que essa atividade teve para o município, uma vez que gerava empregos temporários para uma quantidade significativa de pessoas.

Em relação ao preparo do solo para o cultivo do fumo $100 \%$ dos produtores afirmaram que não recebiam nenhum tipo de insumo repassado pela empresa. Novamente, observa-se uma circunstância atípica, pois o mais comum é que a empresa compradora repasse sementes, defensivos, implementos e orientações para os produtores realizarem as tarefas em conformidade com as exigências necessárias à obtenção de um produto com qualidade satisfatória.

Apurou-se que a principal atividade realizada antes da fumicultura era a agropecuária, cerca de $80 \%$ das pessoas que trabalhavam no fumo já realizavam trabalhos na agricultura e $20 \%$ das pessoas que trabalhavam na fumicultura tinha outros tipos de ocupação. 


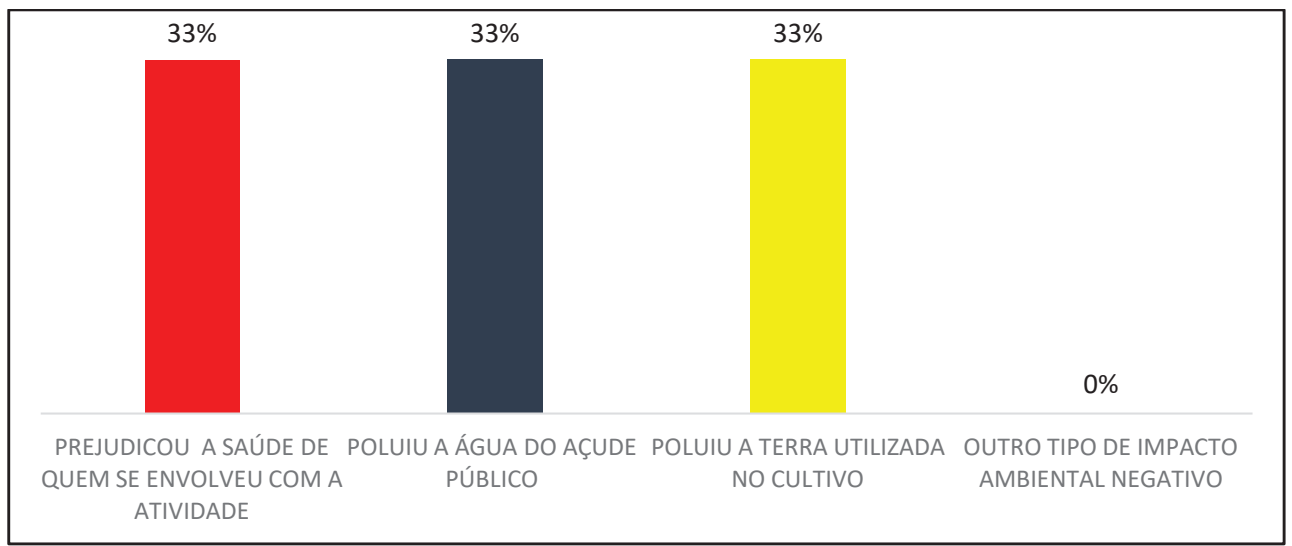

Gráfico 5 - Prejuízos causados pelo cultivo do fumo - Pilões/RN Fonte: Pesquisa de campo (2019).

No Gráfico 5, nota-se a percepção dos trabalhadores sobre os prejuízos que acreditam terem sido provocados pelo cultivo do fumo. $33 \%$ dos entrevistados indicaram que prejudicou a saúde de quem se envolveu com a atividade; $33 \%$ consideram que poluiu a água do açude público e $33 \%$ informaram que poluiu a terra utilizada no cultivo.

Quando indagados sobre a importância da fumicultura para a economia de Pilões/RN, todos (100\%) consideraram muito importante e que o setor comercial local foi o mais beneficiado pela atividade na cidade, mas, no geral, apontaram que a empresa compradora do produto foi a principal beneficiária pelo cultivo de fumo.

Ressalte-se que a atividade também trouxe benefícios para os produtores, pois $80 \%$ conseguiram adquirir bens duráveis através dos ganhos obtidos com a fumicultura, citando-se aquisições de terrenos em área rural e veículos automotores. Ademais, $100 \%$ dos produtores informaram que os recursos obtidos com a atividade sempre eram suficientes para, no mínimo, cobrir os custos e assegurar recursos para a aquisição de mercadorias para o consumo familiar. 


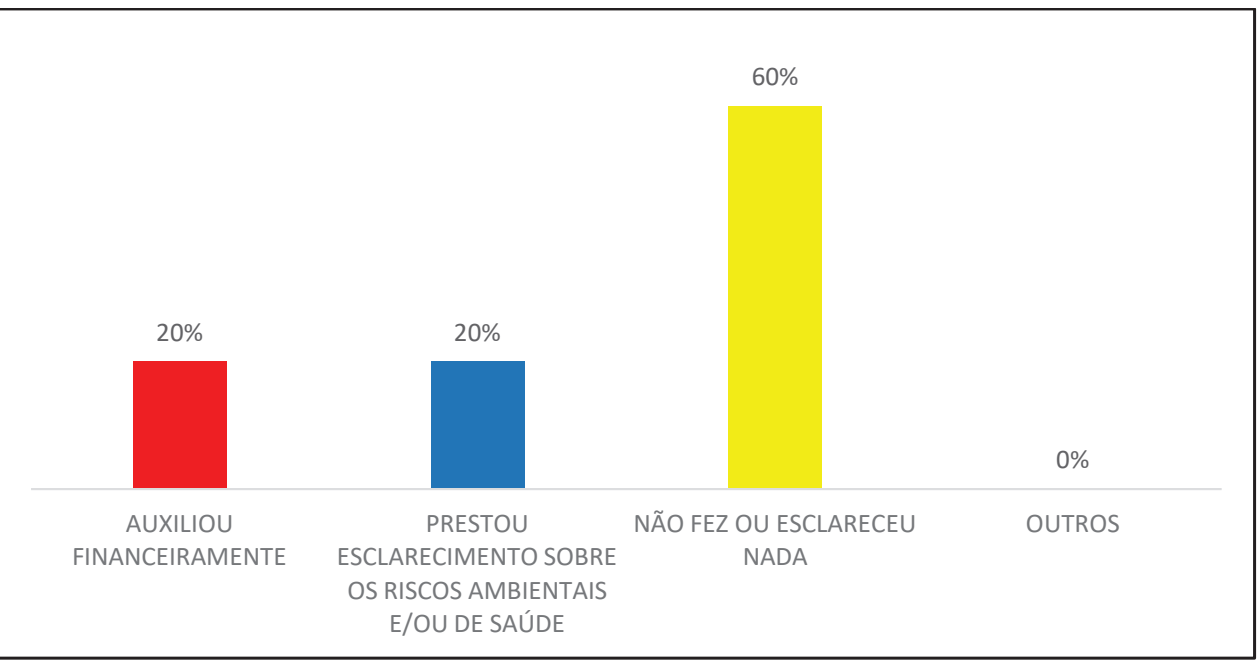

Gráfico 6 - Ação da empresa após o encerramento do cultivo do fumo - Pilões/RN Fonte: Pesquisa de campo (2019).

Ao indagar sobre se houve algum tipo de assistência dada por parte da empresa que comprava o fumo sobre possíveis riscos à saúde ou riscos ambientais provocados pela fumicultura, $60 \%$ dos produtores relatam que a empresa não fez ou esclareceu nada, quando acabou o cultivo simplesmente foi embora. 20\% contam que receberam auxílio financeiro (ou até mesmo tiveram dívidas dispensadas pela a empresa, uma que essa vendia insumos necessários para a produção) e $20 \%$ relataram que a empresa prestou esclarecimentos sobre os riscos ambientais e/ou saúde.

Quando questionados sobre a qualidade de vida após o encerramento da fumicultura, $60 \%$ dos trabalhadores afirmam que a qualidade de vida melhorou, nota-se que não faz falta para essas pessoas, que estas talvez já possuam outra tipo de ocupação. Enquanto $40 \%$ das pessoas declaram que a qualidade de vida piorou quando a atividade teve fim, dizem que os empregos temporários fazem falta.

Com o propósito de coletar mais informações sobre a atividade fumageira em Pilões/RN foram realizadas entrevistas com agentes públicos locais, comerciantes e prestadores de serviços que já estão atuando a mais de dez anos na cidade. Os agentes públicos apresentaram opiniões distintas sobre a fumicultura: parte preferiu apontar a geração de emprego e renda para as famílias como elementos importantes para a economia, uma vez que, as rendas geradas movimentavam a economia local; contudo, também foi salientado que a fumicultura, por utilizar grande volume de água na irrigação, teria acelerado o esvaziamento do Açude Público que é o manancial 
responsável pelo provimento de água para o abastecimento da cidade, além do fato do esvaziamento, também salientaram a suposição de que o uso de insumos químicos na produção do fumo podem ter servido para poluição do reservatório.

As opiniões dos comerciantes e prestadores de serviços foram no sentido de enaltecer a importância da atividade fumageira em vista da geração de emprego e renda para parte da população e consequente rebatimento positivo na economia local. Foi salientado que os recursos recebidos, semanalmente, pelos trabalhadores do fumo movimentavam a economia local, considerando que, segundo foi apurado, gastavam os recursos no comércio e serviços locais. Também informaram que os produtores também usavam as rendas do fumo na própria cidade, potenciação a geração de caixa para os negócios.

O fato é que no município de Pilões/RN, a fumicultura apresentou certa influência econômica, pois, conforme Pontes (2016), a atividade proporcionou rendimentos superiores as outras produções cultivadas pelos agricultores familiares locais. O diferencial positivo de renda, apontado por Pontes (2016), para os fumicultores de Pilões/RN pode ser explicado em virtude da diversificação produtiva que se estabeleceu, isso porque, conforme já mencionado, a atividade não demanda grandes quantidades de terras, assim, os agricultores familiares que passaram a se dedicarem à atividade conseguiram compatibilizar a produção de fumo com as atividades tradicionais (milho-feijão-bovinos).

Por outro lado, a impressão generalizada entre os entrevistados é que o colapso da fumicultura não representou grande impacto para a economia local porque enquanto a renda gerada com atividade (produtores e trabalhadores) minguava, observou-se o crescimento da transferência de recursos para as pessoas através de programas sociais, sendo o PBF apontado como a principal fonte de renda que, de certa forma, supriu a lacuna deixada pelo colapso da atividade fumageira.

\section{Conclusões}

Ressalve-se que não se pretende demonizar a atividade, pois dependendo das circunstâncias em que se estabelece o cultivo pode significar oportunidades na geração de emprego e renda, sobretudo, em áreas carentes de quaisquer atividades econômicas representativas. Por outro lado, também não se desconhece as inúmeras implicações que a atividade, geralmente, produz para aqueles que estão diretamente envolvidos na cadeia produtiva, nem muito menos sobre os conhecidos efeitos negativos do consumo do produto. 
Durante os períodos de estiagem os fumicultores utilizavam a água disponível no principal reservatório hídrico do município, sendo que a água armazenada servia para o abastecimento da cidade e para a irrigação das plantações de fumo. Assim, os produtores, estimulados e ajudados pela empresa, usavam as reservas existentes mesmo durante os períodos em que as chuvas eram escassas.

Pela caracterização da fumicultura praticada em Pilões/RN ficou evidente a utilização de um recurso escasso e armazenado num reservatório público, com destinação prioritária para abastecimento humano, para fins de atendimento e benefício de alguns poucos produtores locais e, principalmente, de uma empresa privada.

Pela ótica econômica se observa que o apoio da empresa e a tecnologia de irrigação fornecida para os produtores representaram uma oportunidade para continuarem produzindo e obtendo alguma renda, mesmo em períodos de estiagem. Ademais, devido as características da economia local, com baixo dinamismo e oferta escassa de empregos e ocupações, tem-se que considerar as ocupações geradas pela atividade.

Durante a fase de levantamento de informações para a elaboração da pesquisa foi possível identificar que as ocupações geradas não eram formalizadas, constituindo-se em diárias realizadas por trabalhadores temporários. Portanto, sem as coberturas legais previstas na legislação trabalhista e, ainda aparentemente, com as atividades laborais sendo exercidas sem o uso de Equipamentos de Proteção Individuais (EPI's), colocando-se em riscos a integridade de trabalhadores temporários e também dos produtores e seus familiares, uma vez que não se verificou distinções no exercício da atividade entre os grupos (trabalhadores temporários/fumicultores/ demais familiares).

Apurou-se que, especialmente em algumas etapas, tinham maiores exigências de pessoal, como na fase da coleta das folhas de fumo, depreendendo-se que a atividade gerava uma quantidade significativa de ocupações, constituindo-se nos períodos de estiagem, provavelmente, na mais importante fonte de oportunidades para ocupação de parte da população.

Pode-se considerar que a produção de fumo em Pilões/RN foi bastante representativa para a economia, sendo plausível admitir, ainda que numa primeira aproximação, que a atividade contribuiu para manter as famílias de fumicultores e trabalhadores temporários, como também com rebatimentos positivos para o comércio e os serviços. Assim, a atividade pode ser percebida a partir das seguintes perspectivas: inicialmente, o cultivo se apresentava como uma saída viável de sobrevivência para a população, especialmente, pela escassez de ofertas de trabalhos na localidade, no entanto, ao mesmo tempo em que garantia uma fonte de renda familiar, também era 
marcada pela opressão ao trabalhador que, além de trabalhar sobre más condições, ainda se deparava com um cenário, comum nesse tipo de cultivo, que é a baixa remuneração da mão de obra.

\section{Notas}

${ }^{1} \mathrm{O}$ fumo era utilizado para realizar a troca por escravos na costa africana (LOPES, 2005).

${ }^{2}$ A entidade surgiu no dia 21 de março de 1955, com sede em Santa Cruz do Sul, no Rio Grande do Sul, primeiramente, chamada de Associação dos Plantadores de Fumo em Folha no Rio Grande do Sul, com foco apenas nos agricultores do Estado. Organizada por produtores de tabaco, em virtude da carência da união entre os agricultores e, visando os interesses na comercialização de tabaco (AFUBRA, 2019).

\section{Referências}

ASSOCIAÇÃO DOS FUMICULTORES DO BRASIL (AFUBRA). 2019. Disponível em: <https://www.afubra.com.br/>. Acesso em: Várias datas.

BRASIL. Lei n ${ }^{\circ} 11.326$, de 24 de julho de 2006. Disponível em <http://www.planalto. gov.br/ccivil_03/_Ato2004-2006/2006/Lei/L11326.htm>. Acesso em: 24 fev. 2020.

BONATO, Amadeu A. A fumicultura no Brasil e a Convenção-Quadro para Controle do Tabaco. Departamento de Estudos Socioeconômicos Rurais, 2007. Disponível em: < http://www.deser.org.br/pub_read.asp?id=109>. Acesso em: 16 mar. 2020.

DAMASCENO, Nagilane Parente; KHAN, Ahmad Saeed; LIMA, Patrícia Verônica Pinheiro Sales. O impacto do Pronaf sobre a sustentabilidade da agricultura familiar, geração de emprego e renda no Estado do Ceará. Revista de Economia e Sociologia Rural, v. 49, n. 1, p. 129-156, 2011. Disponível em: < http://www.scielo.br/scielo. php?pid=S0103-20032011000100006\&script=sci_arttext $>$. Acesso em: 24 mar. 2020.

DUTRA, Éder Jardel da Silva. A cadeia produtiva do tabaco na região Sul do Brasil: perspectivas e horizontes. 2013. Disponível em: $<$ http://www.unisc.br/site/sidr/2013/ Textos/4.pdf>. Acesso em: 14 fev. 2020.

GAMA, Francisco Rerison Ferreira; CARNEIRO, Rosalvo Nobre. A produção do espaço fumicultor no município de Pilões-RN e a territorialização da Souza Cruz SA. 
Revista Geotemas, v. 1, n. 1, p. 33-42, 2011. Disponível em: <http://periodicos.uern. br/index.php/geotemas/article/viewFile/119/110>. Acesso em: 18 mar. 2020.

GIL, Antônio Carlos. Como elaborar projetos de pesquisa. 4 ed. São Paulo: Atlas, 2002.

INSTITUTO BRASILEIRO DE GEOGRAFIA E ESTATÍSTICA (IBGE). Censo Demográfico. 2010. Disponível em: <https://cidades.ibge.gov.br/brasil/rn/piloes/pesqu isa/23/27652? detalhes=true $>$. Acesso em: 18 nov. 2019.

INSTITUTO BRASILEIRO DE GEOGRAFIA E ESTATÍSTICA (IBGE). Censo Agropecuário de 2006. Disponível: <https://sidra.ibge.gov.br/pesquisa/censo-agropecuario/censo-agropecuario-2006/segunda-apuracao>. Acesso em: 25 nov. 2019.

INSTITUTO BRASILEIRO DE GEOGRAFIA E ESTATÍSTICA (IBGE). Histórico Pilões/RN. Disponível: <https://cidades.ibge.gov.br/brasil/rn/piloes/historico>. Acesso em: 25 nov. 2019.

INSTITUTO BRASILEIRO DE GEOGRAFIA E ESTATÍSTICA (IBGE). Panorama de Pilões/RN.2016. Disponível em: <https://cidades.ibge.gov.br/brasil/rn/piloes/panorama>. Acesso em: 18 nov. 2019.

INSTITUTO BRASILEIRO DE GEOGRAFIA E ESTATÍSTICA (IBGE). Produção Agrícola - Lavoura Temporária. Pilões/RN. 2019. Disponível em: <https://cidades.ibge.gov.br/brasil/rn/piloes/pesquisa/14/10193?ano=2017>. Acesso em: 18 nov. 2019.

INSTITUTO BRASILEIRO DE GEOGRAFIA E ESTATÍSTICA (IBGE). Produção Agrícola - Lavoura Temporária. Rio Grande do Norte.2019. Disponível em: <https://cidades.ibge.gov.br/brasil/rn/pesquisa/14/10193?ano=2017>. Acesso em: 18 nov. 2019.

LOPES, Gustavo Acioli. A ascensão do primo pobre: o tabaco na economia colonial da américa portuguesa-um balanço historiográfico. Sæculum-Revista de História, bn. 12, 2005. Disponível em:<http://periodicos.ufpb.br/index.php/srh/article/viewFile/11313/6427>. Acesso em: 15 fev. 2020.

LOPES, Gustavo Acioli. Caminhos e descaminhos do tabaco na economia colonial. Mneme-Revista de Humanidades, v. 5, n. 12, 2004. Disponível em: <http://www. cerescaico.ufrn.br/mneme>. Acesso em: 20 fev. 2020. 
MINISTÉRIO DA AGRICULTURA, PECUÁRIA E ABASTECIMENTO (MAPA). Brasil: $70 \%$ dos alimentos que vão à mesa dos brasileiros são da agricultura familiar. 2017. Disponível em: <http://www.mda.gov.br/sitemda/noticias/brasil-70-dos-alimentos-que-v\%C3\%A3o-\%C3\%A0-mesa-dos-brasileiros-s\%C3\%A3o-da-agricultura-familiar>. Acesso em: 16 jan. 2020.

MATTEI, Lauro. O papel e a importância da agricultura familiar no desenvolvimento rural brasileiro contemporâneo. Rev. Econ. NE, Fortaleza, v.45, p.83-91, 2014. Disponível em: <https://ren.emnuvens.com.br/ren/article/view/500>. Acesso em: 17 mar. 2020.

PONTES, Nadja Cristina. Qualidade do solo e percepção socioambiental de produtores e agentes rurais no cultivo de fumo em Pilões/RN. Dissertação. Mestrado em Ambiente, Tecnologia e Sociedade. Universidade Federal Rural do Semi-Árido - UFERSA. 2016. Disponível em: <https://ppgats.ufersa.edu.br/wp-content/uploads/ sites/47/2016/05/Disserta\%C3\%A7\%C3\%A3o-Nadja-Cristina-Pontes.pdf $>$. Acesso em: 22 nov. 2019.

PROGRAMA DAS NAÇÕES UNIDAS PARA O DESENVOLVIMENTO (PNUD). Atlas do Desenvolvimento Humano no Brasil. Pilões/RN. 2014. Disponível em: $<$ http://www.atlasbrasil.org.br/2013/pt/perfil_m/piloes_rn>. Acesso em: 18 nov. 2019.

Quem são os maiores produtores de tabaco no Brasil. Revista Amanhã. 2016. Disponível em: <http://www.amanha.com.br/posts/view/1741/quem-sao-os-maiores-produtores-de-tabaco-no-brasil>. Acesso em: 26 nov. 2019.

RN SUSTENTÁVEL. Relatório de identificação e mapeamento das aglomerações produtivas do estado do Rio Grande do Norte. 2013. Disponível em: <http://www. rnsustentavel.rn.gov.br/smiv3/site/documentos/arquivo/ea5d60a4d9131854276cc5d9177c599c.pdf>. Acesso em: 18 nov. 2019.

SCHNEIDER, Sérgio; CASSOL, Abel. A agricultura familiar no Brasil. Serie Documentos de Trabajo $N^{\circ}$ 145. Grupo de Trabajo: Desarrollo com Cohesión Territorial. Programa Cohesión Territorial para el Desarrollo. Rimisp, Santiago, Chile. 2013. Disponível em: $<$ https://www.rimisp.org/wpcontent/files_mf/1438617722145Agricu lturaFamiliarBrasil_ShneideryCassol_editado.pdf>. Acesso em: 20 fev. 2020.

SCHNEIDER, Sérgio; CAZELLA, Ademir Antônio; MATTEI, Lauro. Histórico, Caracterização e dinâmica recente do Pronaf - Programa Nacional de Fortalecimento 
da Agricultura Familiar. In: SCHNEIDER, Sérgio; SILVA, Marcelo Kunrath; MARQUES, Paulo Eduardo Morizzi (Org.). Políticas públicas e participação social no Brasil rural. Porto Alegre: UFRGS Editora, 2004.

SILVA, Leonardo Xavier da; LIBARDONI, Paulo; FARIAS, Guilherme Silva de. Descrição e análise do perfil socioeconômico das áreas e dos produtores de fumo em folha no Sul e no Nordeste do Brasil: um estudo baseado nos resultados do Censo Agropecuário 2006. 2013. Disponível em: <http://repositorio.ipea.gov.br/ bitstream/11058/7580/1/RP_Descri\%C3\%A7\%C3\%A3o_2013.pdf >. Acesso em: 17 mar. 2020.

SOUSA, Camila Oliveira; BARRETO FILHO, Boanerges de Freitas. Município de Pilões/RN: A escassez de recursos hídricos no período de 2013 a 2017. Anais $1^{\circ}$ ERESPP, V. 1, 2017. Disponível em: <http://www.editorarealize.com.br/revistas/ erespp/anais.php>. Acesso em: 18 nov. 2019. 